Article

\title{
Multi-Objective Optimization of Process Parameters of Longitudinal Axial Threshing Cylinder for Frozen Corn Using RSM and NSGA-II
}

\author{
Jun Fu ${ }^{1,2,3}$, Haikuo Yuan ${ }^{1,2}$, Depeng Zhang ${ }^{1,2}$, Zhi Chen ${ }^{2,3, *}$ and Luquan Ren ${ }^{1,2}$ \\ 1 Key Laboratory of Bionic Engineering, Ministry of Education, Jilin University, Changchun 130022, China; \\ fu_jun@jlu.edu.cn (J.F.); yuanhaikuo@foxmail.com (H.Y.); zhangdp2410@foxmail.com (D.Z.); \\ lqren@jlu.edu.cn (L.R.) \\ 2 College of Biological and Agricultural Engineering, Jilin University, Changchun 130022, China \\ 3 Chinese Academy of Agricultural Mechanization Sciences, Beijing 100083, China \\ * Correspondence: mac086@126.com; Tel.: +86-0431-85095760-609
}

Received: 1 February 2020; Accepted: 24 February 2020; Published: 1 March 2020

\begin{abstract}
Corn was frozen at harvest time in high-latitude areas, when corn kernel is wetter and more easily broken. When frozen corn was threshed and separated by the longitudinal axial threshing cylinder of a combine harvester, it caused a significantly high kernel damage rate and loss rate. The process parameters of threshing cylinder were optimized using RSM (response surface method) and NSGA-II (Non-Dominated Sorted Genetic Algorithm-II). The drum speed (Ds), feed rate (Fr) and concave clearance $(\mathrm{Cc})$ were determined as the optimized process parameters. The loss rate ( $\mathrm{Lr}$ ) and damage rate (Dr) were indicators of operational performance. The RSM was used to establish a mathematical model between process parameters and indicators. With an elite strategy, NSGA-II was used for multi-objective optimization to obtain the optimal operational performance of the threshing cylinder. Overall, when the drum speed was selected as $384.1 \mathrm{rpm}$, the feed rate as $8.6 \mathrm{~kg} / \mathrm{s}$ and the concave clearance as $40.5 \mathrm{~mm}$, according to the requirement of corn harvest, the best operational performance of the longitudinal axial threshing cylinder on frozen corn was obtained. The Lr was 1.98\% and the Dr was 3.49\%. This result indicated that the applicability of the optimal process parameters and the optimization method of combining NSGA-II and RSM was effective for determining the optimal process parameters. This will provide an optimization method for synchronously reducing the loss rate and damage rate of grain harvesters.
\end{abstract}

Keywords: frozen corn; threshing; multi-objective optimization; process parameters; RSM; NSGA-II

\section{Introduction}

In some high-latitude regions, especially in North America (United States and Canada), Europe (Russia, Belarus and Ukraine) and Asia (China), the temperature is already below freezing point when corn comes into maturity. After corn is frozen, its kernels' mechanical properties are changed. Particularly after a snowfall, corn ears are covered with snow, as shown in Figure 1. Frost is formed on the surface of corn ears, and kernel gaps are filled with frosts. Frozen corn kernels are often damaged by low temperatures [1], which reduces corn quality and causes mildew [2]. The threshing loss rate is improved with a higher kernel splash speed, as the collision coefficient restitution of frozen kernels is increased [3]. Therefore, the mechanical harvesting of frozen corn, especially threshing devices, is also in urgent need of reducing its loss rate and damage rate. 


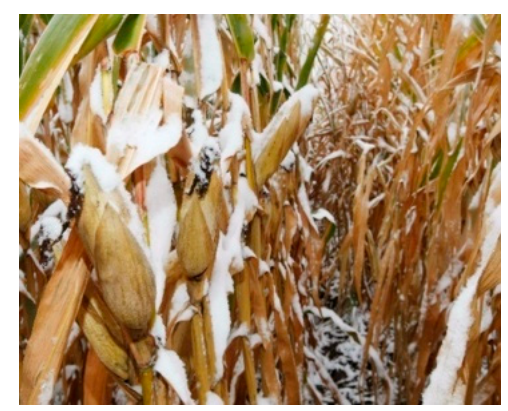

Figure 1. Frozen corn with snow.

Both the loss and damage rate were directly affected by the process parameters of a longitudinal axial threshing cylinder for corn harvesters [4-6]. The drum speed (rotational speed of threshing cylinder, $\mathrm{rpm}$ ), feed rate (weight of corn material inputting the threshing cylinder per unit time, $\mathrm{kg} / \mathrm{s}$ ) and concave clearance (radial distance between the outside of threshing drum and the inside of concave, $\mathrm{mm}$ ) were considered to be the main characteristics of corn combine harvester process parameters [7-10]. Yu et al. [11] established a numerical model of corn threshing cylinder adopting 3-d discrete element method (DEM). The effect of the feeding rate and drum speed on the threshing rate was verified, but this method cannot detect the kernel loss rate or damage rate. Srison et al. [12] found that threshing loss was significantly impacted by concave clearance applied response surface method and central composite design. The threshing loss ranged from $1.2 \%$ to $14.06 \%$, as concave clearance ranged from $10 \mathrm{~mm}$ to $30 \mathrm{~mm}$. Al Sharifi et al. [10] discovered that corn kernel damage was related to kernel moisture content, and the threshing loss was mainly affected by drum speed. A factorial experiment was carried out under a completely randomized design. The results demonstrated that the damage rate was positively correlated with moisture content. The loss rate decreased from $4.939 \%$ to $3.242 \%$ when the drum speed decreased from $400 \mathrm{rpm}$ to $200 \mathrm{rpm}$. Chen et al. [13] adjusted the corn material feed rate based on the designed PID controller of corn harvester forward speed. The field experiment results showed that the lowest loss rate was $0.52 \%$, as the feed rate ranged from $2.82 \mathrm{~kg} / \mathrm{s}$ to $3.10 \mathrm{~kg} / \mathrm{s}$. However, there were few reports on how to optimize the three process parameters (i.e., drum speed, feed rate and concave clearance) together for a corn combine harvester. Additionally, the performance parameters of longitudinal axial threshing cylinders for frozen corn have not been optimized synchronously.

In order to get the exact optimal model and improve the accuracy and efficiency of the optimization, new methods have been applied in other fields. NSGA-II was improved on the basis of NSGA and used for multi-objective optimization. By using the fast non-inferior hierarchical sorting mechanism, the Pareto (optimal solution) front can be approached very well. At the same time, by introducing the crowding degree operator, the dispersion uniformity of the Pareto optimal solution can be guaranteed. The experimental design, ANOVA and optimization algorithm by NSGA-II were combined to optimize the process parameters to save energy consumption during injection molding [14]. Sheet stamping process parameters were optimized by the multi-objective method [15]. Posterior multi-objective optimization by genetic algorithm was used to optimize cutting parameters in turning [16]. The optimal forming quality was obtained through the simulation experiments and multi-objective optimization for the precision forging process parameters [17]. The optimal PID tuning was obtained by various multi-objective optimization algorithms for the paper machine [18]. A study about the multi-objective optimization of a welding process of advanced high-strength steel using an evolutionary algorithm has been discussed [19]. However, the multi-objective optimization method has not been used in combine harvesters, especially for frozen corn threshing.

In order to synchronously reduce the loss rate and damage rate of frozen corn threshing, especially to optimize the process parameters of the longitudinal axial threshing cylinder, a multi-objective optimization method based on the response surface method (RSM) and non-dominated sorted genetic 
algorithm-II (NSGA-II) was proposed in this paper. A central composite design (CCD) was used to obtain test data based on a longitudinal axial threshing cylinder test device. The relationship between process parameters and objectives was established using RSM. NSGA-II was used to facilitate the global search and obtain the Pareto-optimal front. Finally, according to the actual threshing efficiency demand of frozen corn combine harvesters, the optimum value of the process parameters was determined.

\section{Materials and Methods}

\subsection{Material and Equipment}

In view of the temperature of harvest time of frozen corn, the experiment was carried out at $-5.0 \sim-10.0^{\circ} \mathrm{C}$ in the Agricultural Experimental Base of Jilin University (N43 $56^{\prime} 45.99^{\prime \prime}, \mathrm{E} 125^{\circ} 14^{\prime} 52.44^{\prime \prime}$ ) in Changchun, Jilin province, China, in January 2020. The temperature was monitored by a digital thermometer $\left(0.1^{\circ} \mathrm{C}\right.$ accuracy). Corn was collected after frost, and stored at $-5.0^{\circ} \mathrm{C}$. The corn variety used in this experiment was Feitian 358, a native corn variety cultivated by the Dunhuang Seed Industry Co., Ltd in Wuhan, China. The average moisture content of frozen corn kernels was a 27.3\% wet basis, measured using a grain moisture digital tester ( $0.1 \%$ accuracy).

The structure of the longitudinal axial threshing cylinder test device was shown in Figure 2. It was mainly composed of a power unit, feeding hopper, top cover, deflector, concave, threshing drum, frame and collection hopper. In order to clearly illustrate the structures, the top cover was set to be transparent. The threshing drum located in the threshing chamber consisted of a top cover and concave. Rasp bars and round head spikes were fixed onto the threshing drum surface circumferentially in a spiral shape. The concave surrounded the threshing drum at an angle of $180^{\circ}$, and was bolted onto the frame. Its clearance was adjusted with the bolt mounting depth, and ranged from $30 \mathrm{~mm}$ to $50 \mathrm{~mm}$. The concave diameter and area were $656 \mathrm{~mm}$ and $2.266 \mathrm{~m}^{2}$, respectively. The diameter and length of the threshing drum were $408 \mathrm{~mm}$ and $2740 \mathrm{~mm}$, respectively. The drum was powered with an electric motor rated at $55 \mathrm{~kW}$ and a variable frequency controller. Drum speed ranged from $200 \mathrm{rpm}$ to $600 \mathrm{rpm}$, and was measured by an infrared velocimeter ( $0.01 \mathrm{rpm}$ accuracy). The threshing drum inclined by $7^{\circ}$ with the horizontal plane, the same as its tilt angle in a combine harvester. The corn ears feed rate ranged from $5 \mathrm{~kg} / \mathrm{s}$ to $9 \mathrm{~kg} / \mathrm{s}$, according to the normal operating efficiency of a Chinese 5 -row corn harvester. The maximum mass feed rate was determined in pre-tests and controlled by the feeding hopper opening size and conveyor speed. Samples were evenly distributed along the belt conveyor length and continuously fed into the threshing chamber.

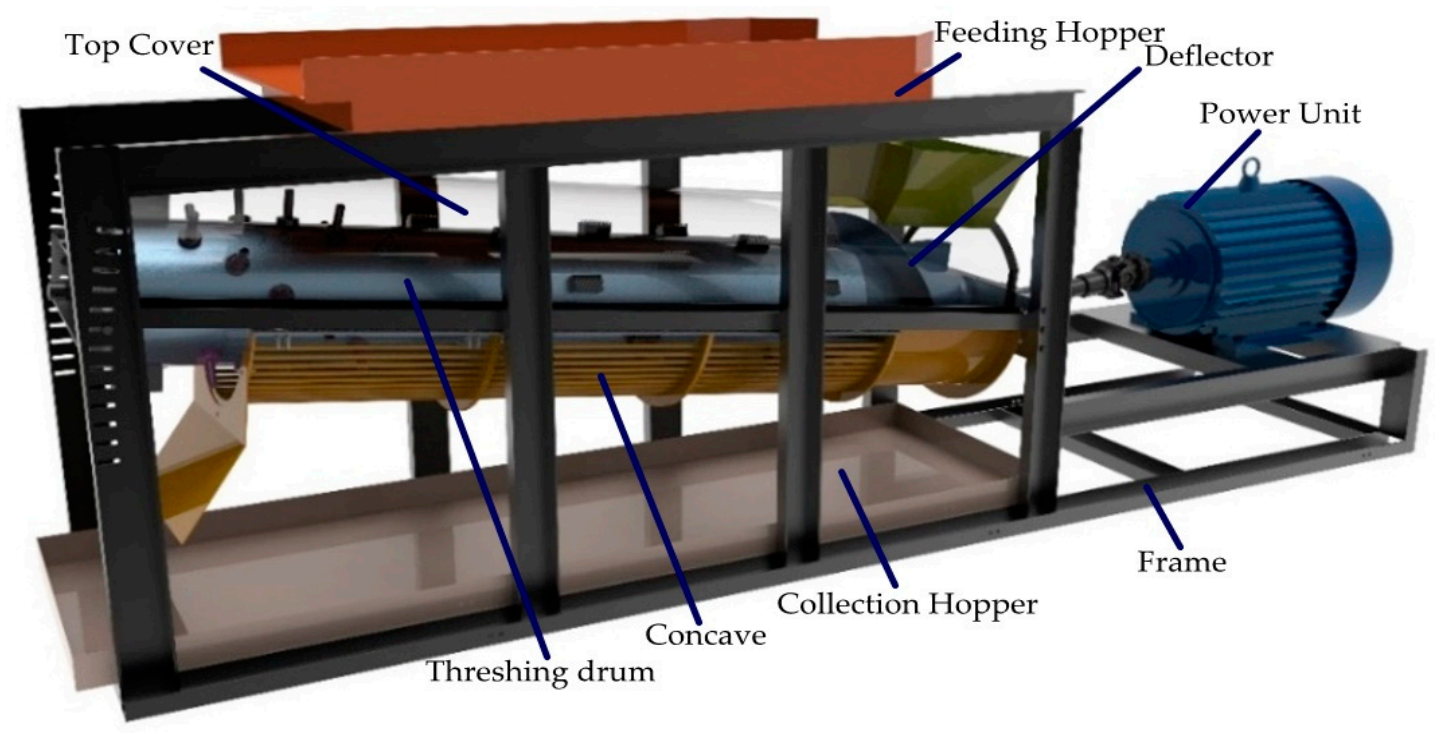

Figure 2. Longitudinal axial threshing cylinder test device. 
Corn ears were subjected to four kinds of mechanical actions by the threshing cylinder successively, including feeding, threshing, separating and expelling. The division of functional areas was shown in Figure 3. Firstly, corn ears were placed on the feeding hopper, and then fed into the threshing chamber and conveyed axially along with the threshing drum. Corn kernels were threshed from ears by the rasp bars, and fell into the collection hopper after being separated from corncobs by a round head spike. Finally, corncobs and leaves were then expelled from the outlets.

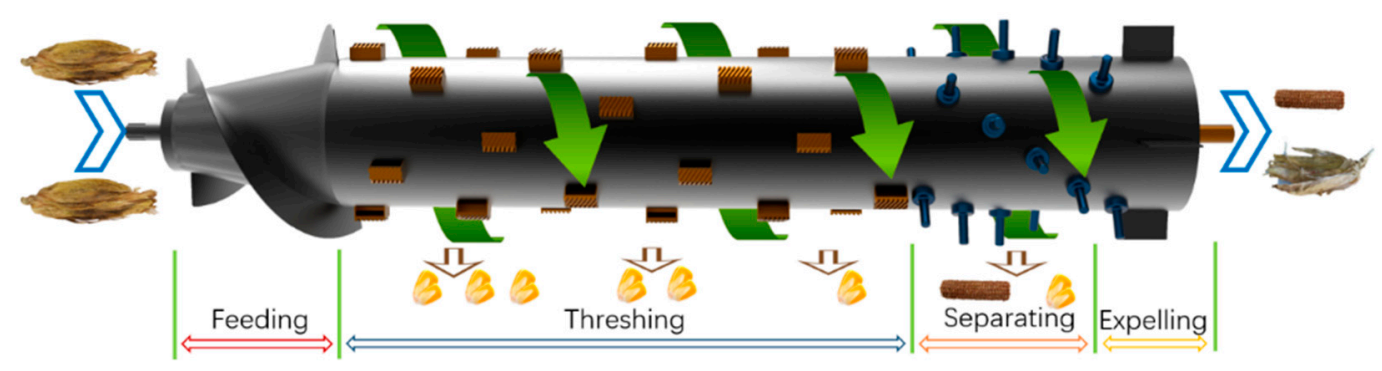

Figure 3. Threshing cylinder.

\subsection{Experiment Design}

The performance of the threshing cylinder depends on several process parameters, such as drum speed, concave clearance and feed rate [20]. The best performance for threshing cylinder is the lowest loss rate and lowest damage rate. An excessively high loss rate means that a large amount of kernels are lost and cannot be collected into silo, and an excessively high damage rate means that there are more broken kernels, which affects the quality of corn kernels and reduces their grade.

Pre-experiments were carried out. When the feed rate was $5 \mathrm{~kg} / \mathrm{s}$ and the drum speed was $200 \mathrm{rpm}$, the un-threshed rate still did not appear. In this paper, the drum speed, concave clearance and feed rate were selected as the independent variables, while the loss and damage rate were taken as the responses. The relationship of the process parameters with the optimization objectives was established. A central composite design (CCD) was used to find the optimal values of the three parameters. In order to describe the nature of the response surface in the optimum region, a central composite design was taken six center points and five levels of each factor, and taken rotatable alpha, so the factor level encodes $(-1.628,-1,0,1,1.628)$ [21]. The process parameters and corresponding range were shown in Table 1. A five-level, three-factor central composite rotatable factorial design is shown in Table 2, which comprises 20 sets of coded conditions for the modeling of the threshing process.

Table 1. Coding of process parameters and their corresponding range.

\begin{tabular}{|c|c|c|c|}
\hline Level & $\begin{array}{l}\text { Drum speed } \\
\text { (Ds)(rpm) }\end{array}$ & Feed rate $(\mathrm{Fr})(\mathrm{kg} / \mathrm{s})$ & $\begin{array}{l}\text { Concave clearance } \\
(\mathrm{Cc})(\mathrm{mm})\end{array}$ \\
\hline 1.682 & 600 & 9 & 50 \\
\hline 1 & 539.19 & 8.19 & 45.95 \\
\hline 0 & 450 & 7 & 40 \\
\hline-1 & 360.81 & 5.81 & 34.05 \\
\hline-1.682 & 300 & 5 & 30 \\
\hline
\end{tabular}


Table 2. Experimental design and result.

\begin{tabular}{cccccc}
\hline Levels & Ds & Fr & Cc & Lr, \% & Dr, \% \\
\hline 1 & -1 & -1 & -1 & 2.495 & 4.282 \\
2 & 1 & -1 & -1 & 6.132 & 5.569 \\
3 & -1 & 1 & -1 & 2.239 & 3.700 \\
4 & 1 & 1 & -1 & 4.741 & 6.114 \\
5 & -1 & -1 & 1 & 4.019 & 2.616 \\
6 & 1 & -1 & 1 & 8.231 & 4.554 \\
7 & -1 & 1 & 1 & 3.614 & 2.634 \\
8 & 1 & 1 & 1 & 5.219 & 3.242 \\
9 & -1.682 & 0 & 0 & 2.350 & 3.042 \\
10 & 1.682 & 0 & 0 & 9.456 & 6.702 \\
11 & 0 & -1.682 & 0 & 4.124 & 3.669 \\
12 & 0 & 1.682 & 0 & 3.670 & 2.162 \\
13 & 0 & 0 & -1.682 & 3.181 & 3.892 \\
14 & 0 & 0 & 1.682 & 5.741 & 2.362 \\
15 & 0 & 0 & 0 & 2.477 & 3.771 \\
16 & 0 & 0 & 0 & 2.702 & 3.936 \\
17 & 0 & 0 & 0 & 2.685 & 4.168 \\
18 & 0 & 0 & 0 & 3.725 & 3.582 \\
19 & 0 & 0 & 0 & 2.673 & 4.739 \\
20 & 0 & 0 & 0 & 2.723 & 3.959 \\
\hline \multicolumn{7}{r}{} & Lr loss rate, Dr = damage rate &
\end{tabular}

Every test was repeated six times, and the total amount of frozen corn in the overall experiment with CCD was approximately $2625 \mathrm{~kg}$. After each test, kernels in the collection hopper and outlets were weighed by an electronic balance. Corn kernels obtained from the outlets were known as loss grains. $2 \mathrm{~kg}$ of kernels were randomly weighed from collection hopper to calculate the damage rate. According to Paulsen's research [22], corn kernel threshing damage only included broken grains, rather than grains with stress cracks, meaning the damaged grains were picked out by an artificial eye. The formulae for the calculation of the loss rate $(\mathrm{Lr})$ and damage rate $(\mathrm{Dr})$ were as follows:

$$
\begin{aligned}
& L r=\frac{W_{l}}{W_{t}} \times 100 \\
& D r=\frac{W_{d}}{2} \times 100
\end{aligned}
$$

In the formula, $W_{l}$ was the weight of kernels collected in outlets, $\mathrm{kg}, W_{t}$ was the total weight of kernels from collection hopper and outlets in each test, $\mathrm{kg}$, and $W_{d}$ was the weight of the broken kernels in the sample kernels, $\mathrm{kg}$.

\subsection{Multi-objective Optimization Methodology}

\subsubsection{Optimization Process}

The procedure diagram of the process parameters optimization of the threshing cylinder used in the current work was shown in Figure 4. As described previously, three process parameters for objective functions related to drum speed, feed rate and concave clearance were selected for optimization. There were two objectives, so this was multi-objective optimization research. It appears that other optimization targets may be reduced when optimizing one target. Therefore, there was usually an optimal solution set for multi-objective optimization, and the optimal solution was integrated as a Pareto optimal solution. 


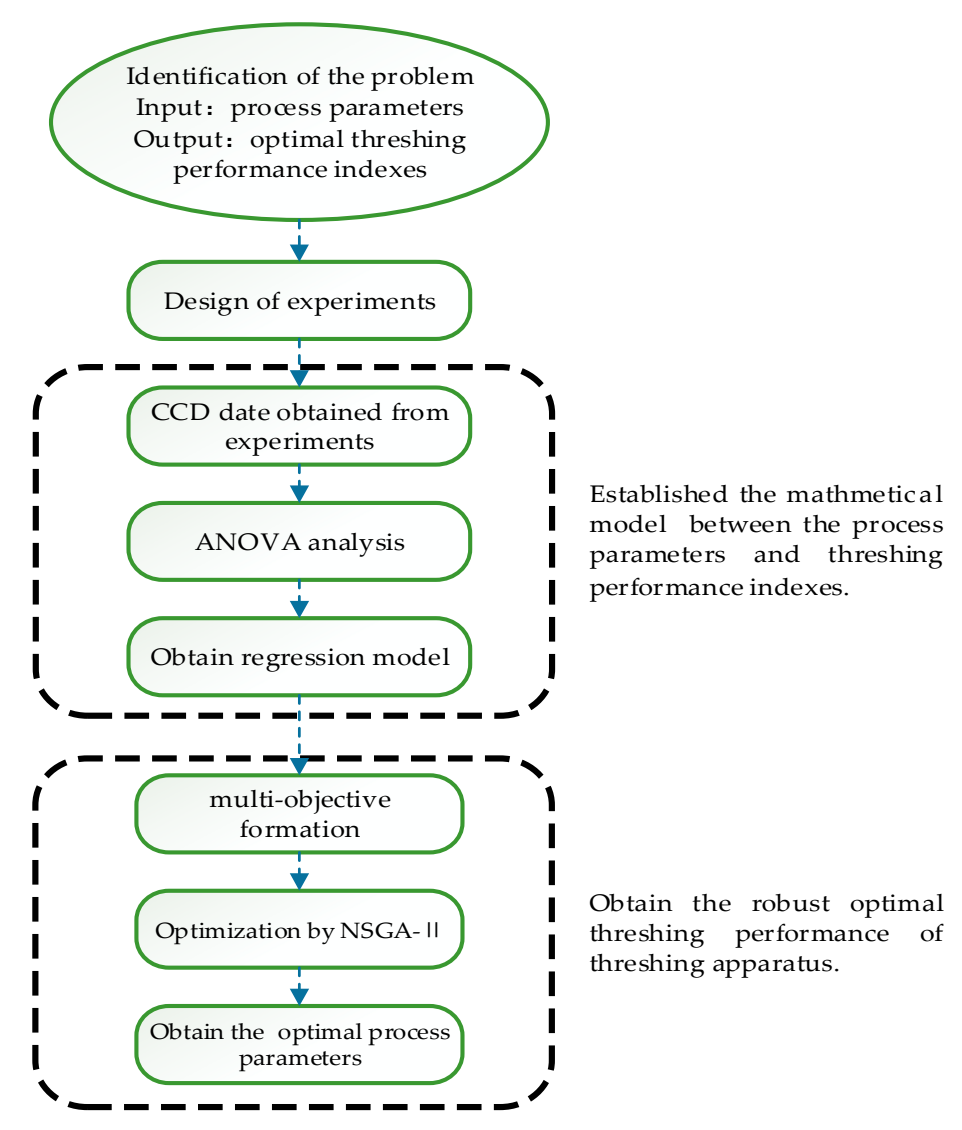

Figure 4. Procedure diagram of the optimization.

In this paper, a Pareto optimal solution was obtained by combining with RSM and NSGA-II. RSM was used to experiment and establish the relationship between the process parameters and objectives. NSGA-II was used to facilitate the global search and obtain the Pareto-optimal front. The optimization steps were as follows:

Step 1: To identify the problem, and input process parameters. Then to output optimal operational performance indexes.

Step 2: To design the experiments by CCD.

Step 3: To obtain a date from threshing experiments.

Step 4: ANOVA analysis with quadratic model for experiments results, then to establish the regression model of factors with objectives.

Step 5: To calculate the Pareto optimal front and obtain the optimum process by NSGA-II.

Step 6: To verify the optimum process parameter by threshing experiments.

\subsubsection{Response Surface Method}

The response surface method was commonly used in experimental design. Its principle was to use the multivariate quadratic regression equation to express the functional relationship between factors and response values. CCD was one of the methods of response surface optimization. CCD can reduce experimental times required to evaluate the main effect of each parameter and their interactions. Because of the large number of corns required for each test and the wide range of process parameters, the CCD test was selected as the test method. Equation (3) shows the quadratic polynomial equation often used in the response surface method.

$$
y=\beta_{0}+\sum_{i=1}^{n} \beta_{i} x_{i}+\sum_{i=1}^{n} \beta_{i i} x_{i}^{2}+\sum_{i=1}^{n} \beta_{i j} x_{i} x_{j}+\varepsilon
$$


In the formula, $y$ was the response, $x$ was the independent variable, $\beta_{0}$ was the constant coefficient, $\beta_{i}$ was the linear term coefficient, $\beta_{i i}$ was the quadratic term coefficient and $\beta_{i j}$ was the interaction term coefficient. In this experiment, indicators of operational performance, namely the loss rate and damage rate, were the response, and were represented by Lr and Dr, respectively. Moreover, the drum speed, feed rate and concave clearance were the independent variables, and were represented by Ds, Fr and Cc, respectively.

\subsubsection{Non-Dominated Sorted Genetic Algorithm-II (NSGA-II)}

In order to obtain the best operational performance of the threshing cylinder in this study, the non-dominated sorting genetic algorithm II (NSGA-II) was utilized [23]. This optimization algorithm was of low computational complexity and elite strategy. It was not only applied to detect the Pareto-optimal front for non-convex multi-objective problems, but also could avoid being too time-consuming. The Pareto-optimal solutions could be obtained in a single run only.

The detailed procedure of the NSGA-II was shown in Figure 5. As mentioned in the flow chart, the fitness functions of the optimization algorithm were determined by the regression model between process parameters to the indictors. Genetic operators, including crossover and mutation, were applied in order to generate a new population. Then, the elitist strategy was conducted to save the better part of the newly generated population for each cycle. Finally, the optimization process was wrapped up with the condition of the repetitions number.

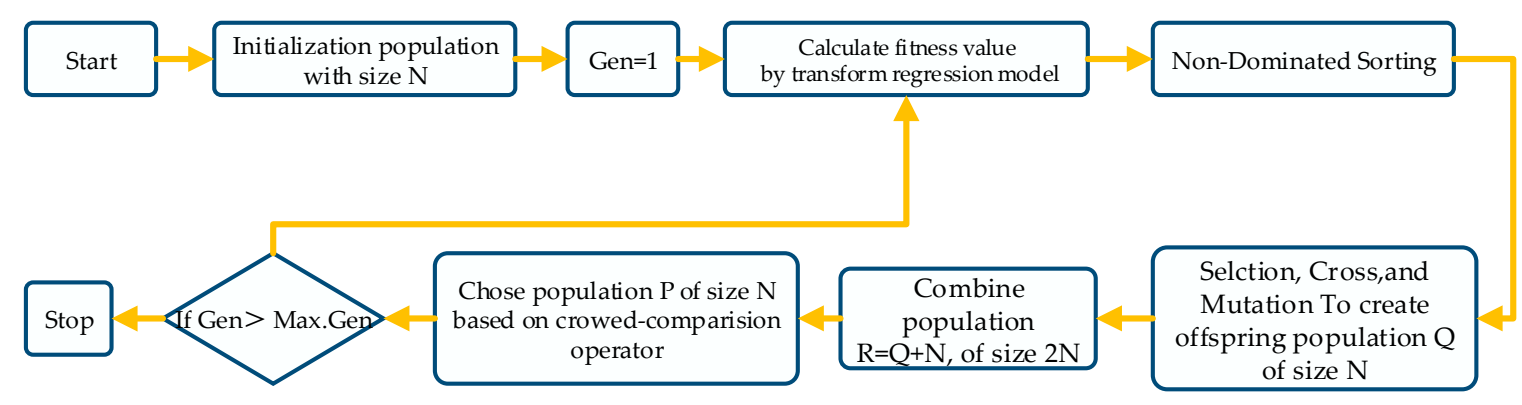

Figure 5. Flowchart of the NSGA-II.

Two functions were used in this algorithm. The first was the non-dominated sorting function, and the second was the crowding distance function. This subprogram took population members as input, and put them into fronts in proportion to their ranks. The second function was designed to avoid the accumulation of population members in a limited distance. On the other hand, there were no blank intervals in the domain due to using a crowding distance function. This function was utilized for comparison between members of a front which had equal ranks. For each reference point, the normalization Euclidean distance of each solution of the front was compared with the first, the previous, the next and the last member of the population. Normalization was used to avoid the problem that the objectives were on different scales.

\section{Results and Discussion}

\subsection{ANOVA Analysis}

According to the result of CCD, the threshing cylinder operational performance experiments was performed, and the values of the different response variables were obtained. The results were presented in Table 2. The loss rate (Lr) ranged from $2.495 \%$ to $8.231 \%$, while the damage rate (Dr) ranged from $2.634 \%$ to $6.114 \%$. These results were consistent with the investigation of the maize ear threshing process [24]. However, both performance parameters cannot be minimized simultaneously at this time. The response variables obtained from the simulations were then analyzed by multiple 
quadratic regressions to determine the mathematical models with the best fits. The adequacy and reliability of the regression models were also tested using the analysis of variance (ANOVA).

Statistical significance was determined by the ANOVA with quadratic models. The results from ANOVA of the Lr were listed in Table 3. They were evaluated by the coefficient of multiple determination $\left(R^{2}\right)$. When the value of $R^{2}$ was 0.9517 , it implied that the quadratic model was not reflected the $0.0483 \%$ of total $\mathrm{Lr}$ variation. When the F-value was 21.89 , it expressed that the regression model of $\mathrm{Lr}$ reached great significance for the performance optimization of threshing cylinders. In Tables 3 and 4 , single asterisks indicated that the model terms were significant levels $(P \leq 0.05)$, while double asterisks indicated that the model terms were very significant levels $(\mathrm{P} \leq 0.01)$ and triple asterisks indicated that the model terms were an extremely significant level $(\mathrm{P} \leq 0.001)$. In Table 3 , it can be found that significant level terms included the linear terms of $\mathrm{Fr}$, the very significant level terms included the linear terms of $\mathrm{Cc}_{\mathrm{c}}$ and the quadratic terms of $(\mathrm{Cc})^{2}$, and the extremely significant level terms included the linear terms of Ds and the quadratic terms of (Ds) ${ }^{2}$. Therefore, the most significant term was the linear term, and the interaction term was the least significant for the Lr. In addition, Ds was the strongest factor affecting Lr. These results indicated that the Lr would be improved significantly with the increase of Ds. Pishgar-Komleh et al. [25] also found that the effects of combine cylinder speed on the threshing loss were significant, at a level of $1 \%$. Their results also indicated that the loss rate was improved from $4.7 \%$ to $5.28 \%$, with the drum speed increasing from $400 \mathrm{rpm}$ to $500 \mathrm{rpm}$.

Table 3. Analysis of variance for loss rate.

\begin{tabular}{ccccccc}
\hline Source & SS & Df & MS & F-Value & p-value & \\
\hline Model & 71.64 & 9 & 7.96 & 21.89 & $<0.0001$ & $* * *$ \\
Ds & 41.85 & 1 & 41.85 & 115.10 & $<0.0001$ & $* * *$ \\
Fr & 2.49 & 1 & 2.49 & 6.84 & 0.0258 & $*$ \\
Cc & 7.00 & 1 & 7.00 & 19.27 & 0.0014 & $* *$ \\
Ds-Fr & 1.75 & 1 & 1.75 & 4.82 & 0.0529 & \\
Ds-Cc & 0.013 & 1 & 0.013 & 0.036 & 0.8539 & \\
Fr-Cc & 0.39 & 1 & 0.39 & 1.08 & 0.3236 & \\
Ds & 15.18 & 1 & 15.18 & 41.74 & $<0.0001$ & $* * *$ \\
Fr $^{2}$ & 1.45 & 1 & 1.45 & 3.98 & 0.0739 & \\
Cc $^{2}$ & 3.84 & 1 & 3.84 & 10.57 & 0.0087 & $* *$ \\
Residual & 3.64 & 10 & 0.36 & & & \\
Lack of Fit & 2.64 & 5 & 0.53 & 2.64 & 0.1551 & \\
Pure Error & 1.00 & 5 & 0.20 & & & \\
Cor Total & 75.27 & 19 & & & & \\
\hline
\end{tabular}

$\mathrm{SS}=$ sequential sum of squares; $\mathrm{Df}=$ degrees of freedom; $\mathrm{MS}=$ mean squares; $\mathrm{F}=$ Fischer's variance ratio; $\mathrm{p}=$ probability value; ${ }^{*}$ Significant $(\mathrm{p}<0.05) ;{ }^{* *}$ Very significant $(\mathrm{p}<0.01) ;{ }^{* * *}$ Very significant $(\mathrm{p}<0.001)$.

The results from ANOVA of the Dr were listed in Table 4. The results were evaluated by the coefficient of multiple determination $\left(R^{2}\right)$. When the value of $R^{2}$ was 0.8768 , it implied that the quadratic model was not reflected the $0.1232 \%$ of total Dr variation. When the F-value was 7.91 , it expressed that the regression model of Dr reached great significance for the performance optimization of the threshing cylinder. In Table 4, it can be found that significant level terms included the linear terms of $(\mathrm{Ds})^{2}$, while the very significant level terms included the linear terms of Cc and the extremely significant level terms included the linear terms of Ds. Therefore, the most significant term was the linear term, and the interaction term was the least significant for the Dr. In addition, Ds also was the strongest factor affecting the Dr. The previous research also found that corn kernel damage increased from $10 \%$ up to $23 \%$, with rasp bar movement speed varying from 12 to $20 \mathrm{~m} / \mathrm{s}$ [24]. 
Table 4. Analysis of variance for damage rate.

\begin{tabular}{ccccccc}
\hline Source & SS & Df & MS & F-Value & p-value & \\
\hline Model & 23.58 & 9 & 2.62 & 7.91 & 0.0017 & $* *$ \\
Ds & 11.26 & 1 & 11.26 & 34.01 & 0.0002 & $* * *$ \\
Fr & 1.09 & 1 & 1.09 & 3.30 & 0.0993 & \\
Cc & 6.19 & 1 & 6.19 & 18.68 & 0.0015 & $* *$ \\
Ds-Fr & $5.164 \mathrm{E}-003$ & 1 & $5.164 \mathrm{E}-003$ & 0.016 & 0.9031 & \\
Ds-Cc & 0.17 & 1 & 0.17 & 0.50 & 0.4944 & \\
Fr-Cc & 0.20 & 1 & 0.20 & 0.60 & 0.4577 & \\
Ds $^{2}$ & 2.30 & 1 & 2.30 & 6.94 & 0.0250 & $*$ \\
Fr $^{2}$ & 1.23 & 1 & 1.23 & 3.73 & 0.0824 & \\
Cc $^{2}$ & 0.68 & 1 & 0.68 & 2.06 & 0.1814 & \\
Residual & 3.31 & 10 & 0.33 & & & \\
Lack of Fit & 2.51 & 5 & 0.50 & 3.12 & 0.1186 & \\
Pure Error & 0.80 & 5 & 0.16 & & & \\
Cor Total & 26.89 & 19 & & & & \\
\hline
\end{tabular}

$\mathrm{SS}=$ sequential sum of squares; $\mathrm{Df}=$ degrees of freedom; MS = mean squares; $\mathrm{F}=$ Fischer's variance ratio; $\mathrm{p}=$ probability value; ${ }^{*}$ Significant $(\mathrm{p}<0.05) ;{ }^{* *}$ Very significant $(\mathrm{p}<0.01) ;{ }^{* * *}$ Very significant $(\mathrm{p}<0.001)$.

\subsection{Regression Models of Responses}

Based on the results of the experiments in Table 2, experimental data were analyzed and fitted with the quadratic polynomials that were obtained using the regression model.

The $\mathrm{Lr}$ regression response surface models were represented as:

$$
\begin{aligned}
& L r=28.15192-0.062565 D s-0.26050 F r-0.79458 C c-4.41088 \times 10^{-3} D s \\
& -7.59398 \times 10^{-5} D s \times C c-0.031304 F r \times C c+1.29006 \times 10^{-4} D s^{2}+0.22419 F r^{2} \\
& +0.014604 C c^{2}
\end{aligned}
$$

The Dr regression response surface models were represented as:

$$
\begin{aligned}
& D r=-16.08260-0.022436 D s+3.65587 F r+0.65757 C c-2.39532 \times 10^{-4} D s \times F r \\
& -2.72059 \times 10^{-4} D s \times C c-0.022225 F r \times C C+5.01967 \times 10^{-5} D s^{2}-0.20692 F r^{2} \\
& -6.15949 \times 10^{-3} C c^{2}
\end{aligned}
$$

\subsection{Multi-objective Optimization Model}

The optional operation performance of threshing cylinder should be of low grain loss rate, and the damage rate as soon as possible. In this research, the process parameters of the Ds, Fr and Cc were used as design variables. Based on the pre-experiment, the drum speed was set as $300 \mathrm{rpm} \leq \mathrm{Ds} \leq$ $600 \mathrm{rpm}$, the feed rate was set as $5 \mathrm{~kg} / \mathrm{s} \leq \mathrm{Fr} \leq 9 \mathrm{~kg} / \mathrm{s}$ and the concave clearance was set as $30 \mathrm{~mm} \leq \mathrm{Cc}$ $\leq 50 \mathrm{~mm}$. When process parameters were changed, the kernel loss rate and the damage rate developed contradictorily. Therefore, the objective function and constraint function of the optimization problem were as follows:

$$
\left\{\begin{array}{c}
\min [\operatorname{Lr}(D s, F r, C c), D r(D s, F r, C c)] \\
300 r p m \leq D s \leq 600 r p m \\
5 \mathrm{~kg} / \mathrm{s} \leq F \mathrm{r} \leq 9 \mathrm{~kg} / \mathrm{s} \\
30 \mathrm{~mm} \leq C \mathrm{c} \leq 50 \mathrm{~mm}
\end{array}\right.
$$

\subsection{Effect of Interaction}

\subsubsection{Effect of Interaction of Factors on Lr}

In order to observe certain curvature regions and interactions among the process parameters, the response surfaces of Equation (4) were modeled through robust parameter design. Lr was presented 
in Figure 6 on the experimental region, with hold values specified in each graph. From the contour map, it was found that the central color of Figure $6 a$ was obviously darker than those of Figures $6 \mathrm{~b}$ and $6 c$, and the trend of change was stronger, as was the p-value of each item in Table 3; this indicated that the interaction was more significant.

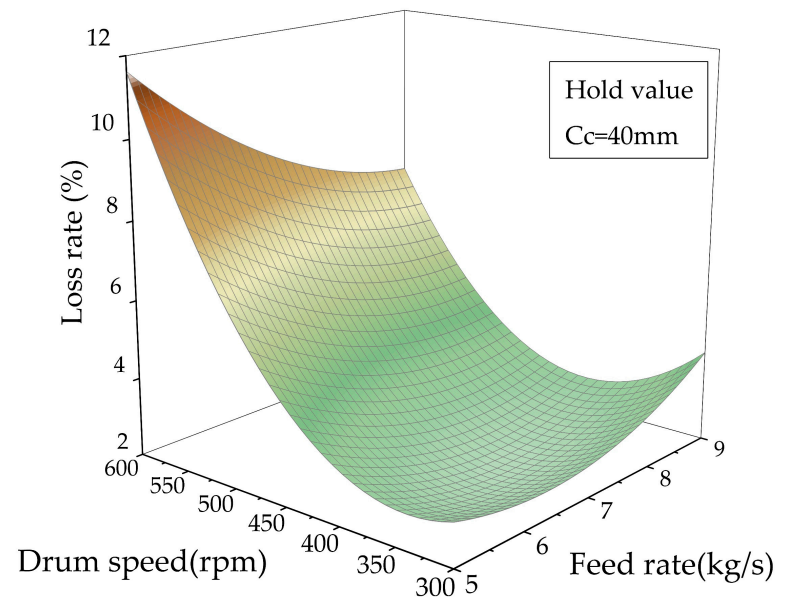

(a)

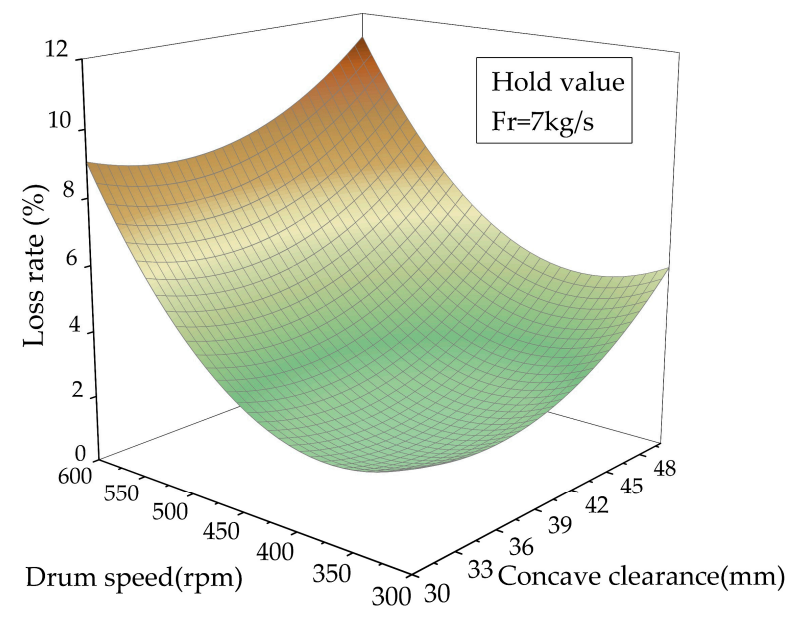

(b)

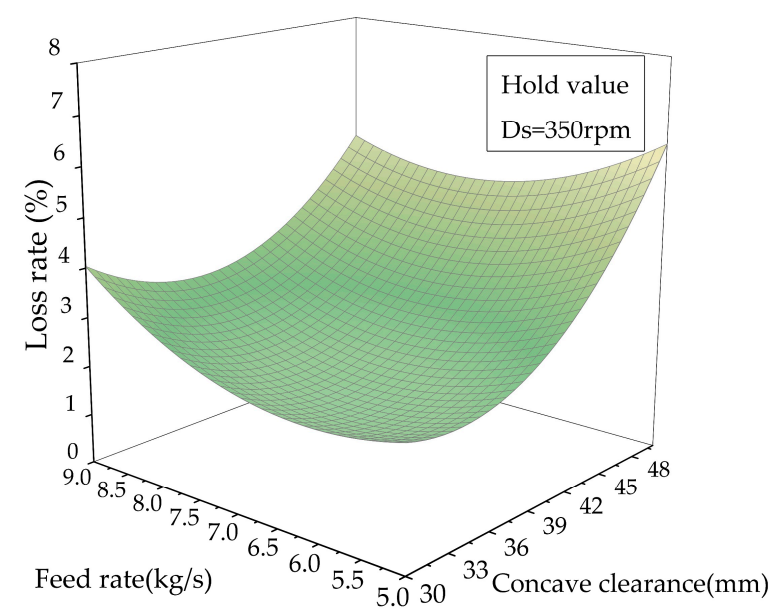

(c)

Figure 6. Response surface diagrams of interaction: (a) Interaction of Ds-Fr; (b) interaction of Ds-Cc. (c) Interaction of Fr-Cc. 


\subsubsection{Effect of Interaction of Factors on Dr}

For the observation of certain curvature regions and interactions among the process parameters, the response surfaces of Equation (5) were modeled through robust parameter design. Dr was presented in Figure 7 on the experimental region, with hold values specified in each graph. The contour map showed that the central colors of Figure $7 \mathrm{~b}$ and $7 \mathrm{c}$ were obviously darker than those of Figure $7 \mathrm{a}$, and the trend of change was stronger, as was p-value of each item in Table 4 . This indicates that the interaction was more significant.

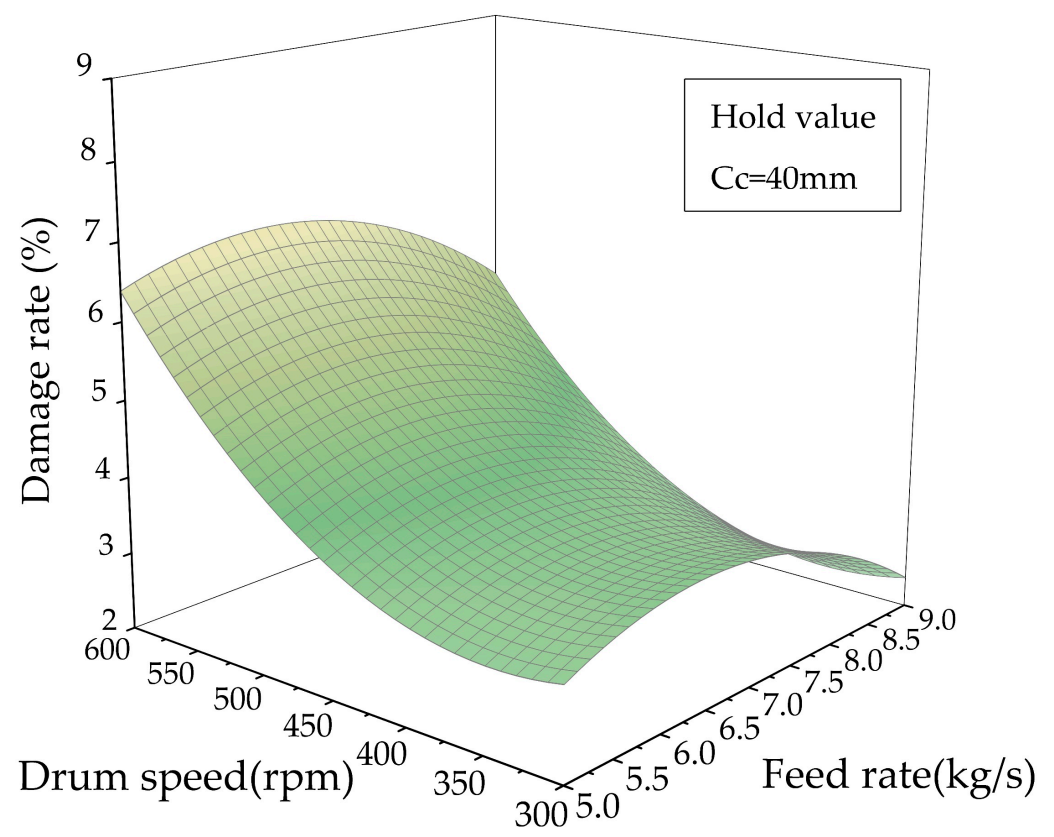

(a)

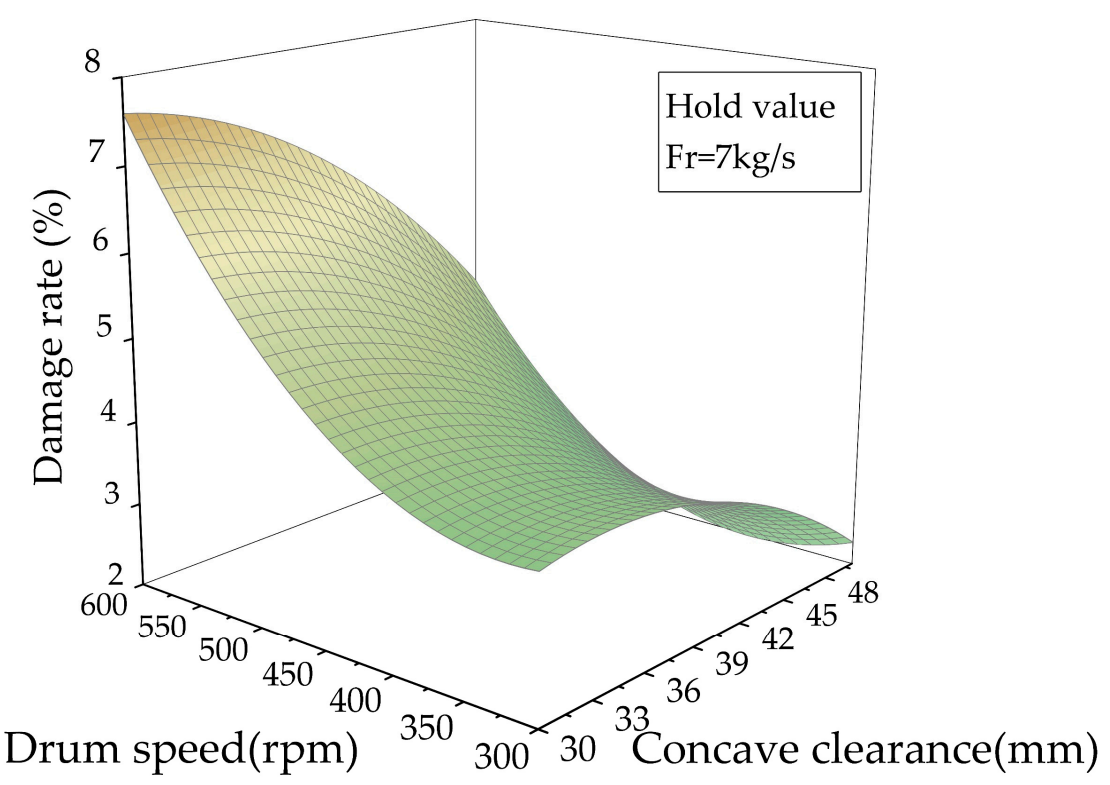

(b)

Figure 7. Cont. 


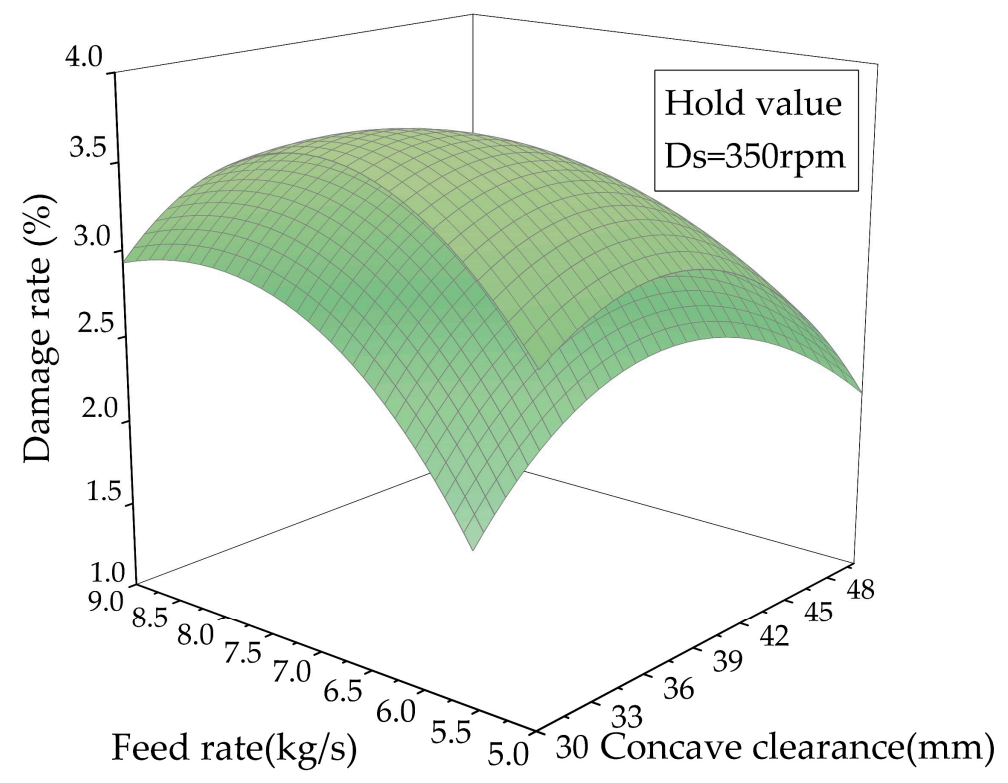

(c)

Figure 7. Response surface diagrams of interaction: (a) Interaction of Ds-Fr; (b) interaction of Ds-Cc. (c) Interaction of Fr-Cc.

\subsection{Optimization by NSGA-II}

The Pareto frontier obtained by solving the optimization model with the NSGA-II algorithm was shown in Figure 8. Lr was represented on the abscissa, and Dr was represented on the ordinate. For multi-objective optimization problems, it was impossible to make each objective optimal at the same time. However, coordination and tradeoffs between the objectives can be performed to satisfy each objective as much as possible. This means that all solutions on the optimal frontier can be used for scheme optimization. According to the reference of GB/T 21961-2008 (State Standard of the People's Republic of China of Test Methods for Maize Combine Harvester) and GB/T 21962-2008 (State Standard of the People's Republic of China of Technical Requirements for Maize Combine Harvester), the permissible range of $\mathrm{Lr}$ and $\mathrm{Dr}$ is 5\% and 5\%, respectively. Dr is less important than Lr within the permissible range, therefore the weight of $\mathrm{Lr}$ is greater than weight of Dr. In order to make $\mathrm{Lr}$ and Dr as optimal as possible, the drum speed was selected as $384.1 \mathrm{rpm}$, the feed rate as $8.6 \mathrm{~kg} / \mathrm{s}$ and the concave clearance as $40.5 \mathrm{~mm}$, according to the requirement of corn harvest. Therefore, the best operational performance of a longitudinal axial threshing cylinder on frozen corn was obtained. The $\mathrm{Lr}$ was $1.98 \%$ and the Dr was $3.49 \%$. Under this condition, Lr has reached the normal threshing indexes of threshing corn at normal temperatures. Dr was lower than the normal threshing indexes of threshing corn at normal temperatures.

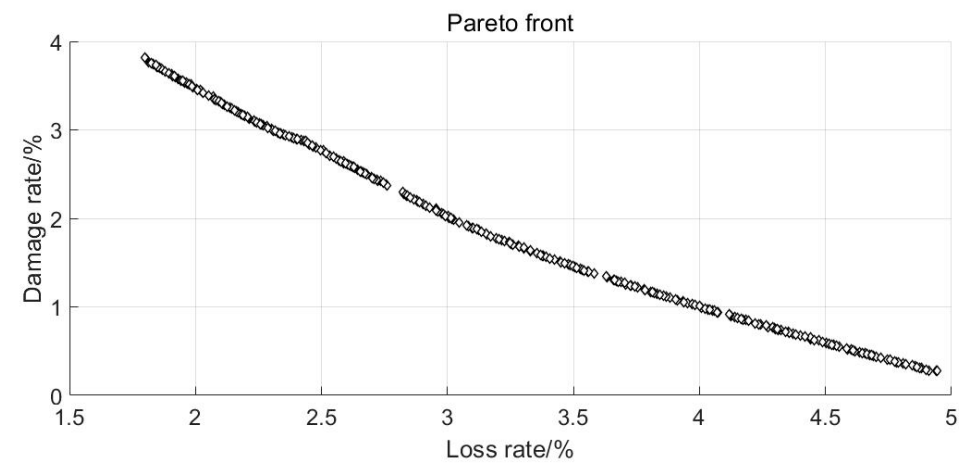

Figure 8. Pareto-Pareto optimal sets with NSGA-II. 


\subsection{Verification Experiment}

To validate the optimal process parameters, the threshing experiment was repeated under the optimal conditions. The valid test was repeated three times to obtain the result. The results were presented in Table 5. The average Lr reached 1.93\%, and the average Dr reached 3.40\%. The errors were within $\pm 5 \%$. This result indicated that the applicability of the optimal process parameters and the optimization method of combining NSGA-II and RSM was effective to determine the optimal process parameters.

Table 5. Results of the validation tests.

\begin{tabular}{cccccc}
\hline Trail & $\mathbf{1}$ & $\mathbf{2}$ & $\mathbf{3}$ & Error Value & Average Value \\
\hline $\mathrm{Lr} / \%$ & 1.8962 & 1.9516 & 1.9554 & 0.0331 & 1.9344 \\
$\mathrm{Dr} / \%$ & 3.5122 & 3.4483 & 3.2521 & 0.1355 & 3.4042 \\
\hline
\end{tabular}

\section{Conclusions}

The mathematical model of the multi-objective optimization of longitudinal axial threshing cylinders for frozen corn was established based on the second-order response surface method (RSM). Furthermore, the Non-Dominated Sorted Genetic Algorithm-II (NSGA-II) was used to obtain the Pareto-optimal solutions. It was clearly found that drum speed, feed rate and concave clearance shake amplitude significantly affected operational performance. As a result, Ds was the strongest factor affecting both $\mathrm{Lr}$ and Dr. In other words, the threshing quality of frozen corn was most affected by drum speed (Ds) in a longitudinal axial combine harvester.

The optimum values of the process parameters of threshing cylinders for frozen corn were determined. The drum speed was $384.1 \mathrm{rpm}$, the feed rate was $8.6 \mathrm{~kg} / \mathrm{s}$ and the concave clearance was $40.5 \mathrm{~mm}$. Accordingly, the $\mathrm{Lr}$ was $1.98 \%$ and $\mathrm{Dr}$ was $3.49 \%$. The verification experiment determined that the $\operatorname{Lr}$ was $1.93 \%$ and $\operatorname{Dr}$ was $3.40 \%$. The feasibility of the proposed multi-objective optimization method of process parameters in agriculture machinery was verified by RSM and NSGA-II.

After the optimization, the loss rate and damage rate of threshing performance for frozen corn were reduced in the demand for combine harvesters. This will provide an optimization method for synchronously reducing the loss rate and damage rate for grain harvesters. This multi-objective optimization method, combining RSM and NSGA-II, may be widely used in other agricultural machinery.

Author Contributions: Conceptualization, J.F.; methodology, J.F.; validation, H.Y. and D.Z.; investigation, H.Y. and D.Z.; resources, L.R.; writing-original draft preparation H.Y.; writing-review and editing, J.F.; supervision, Z.C., and L.R.; project administration, J.F.; funding acquisition, J.F. All authors have read and agreed to the published version of the manuscript.

Funding: This research was funded by the National Key Research and Development Plan of China, grant number 2017YFD0700302.

Acknowledgments: The authors are grateful for the frozen corn provided by the Experimental Base of Agriculture of Jilin University.

Conflicts of Interest: The authors declare no conflict of interest.

\section{References}

1. Zhang, J.; Dai, L.; Cheng, F. Classification of frozen corn seeds using hyperspectral VIS/NIR reflectence imaging. Molecules 2019, 24, 149. [CrossRef]

2. Su, Y.; Cui, T.; Zhang, D.; Xia, G.; Gao, X.; He, X.; Xu, Y. Damage resistance and compressive properties of bulk maize kernels at varying pressing factors: Experiments and modeling. J. Food Process Eng. $2019,42$. [CrossRef]

3. Wang, L.; Wu, B.; Wu, Z.; Li, R.; Feng, X. Experimental determination of the coefficient of restitution of particle-particle collision for frozen maize grains. Powder Technol. 2018, 338, 263-273. [CrossRef] 
4. Gu, R.-L.; Huang, R.; Jia, G.-Y.; Yuan, Z.-P.; Ren, L.-S.; Li, L.; Wang, J.-H. Effect of Mechanical Threshing on damage and vigor of maize seed threshed at different moisture contents. J. Integr. Agric. 2019, 18, 1571-1578. [CrossRef]

5. Šotnar, M.; Pospíšil, J.; Mareček, J.; Dokukilová, T.; Novotný, V. Influence of the combine harvester parameter settings on harvest losses. Acta Technol. Agric. 2018, 21, 105-108. [CrossRef]

6. Yang, L.; Cui, T.; Qu, Z.; Li, K.H.; Yin, X.W.; Han, D.D.; Yan, B.X.; Zhao, D.Y.; Zhang, D.X. Development and application of mechanized maize harvesters. Int. J. Agric. Biol. Eng. 2016, 9, 15-28. [CrossRef]

7. Fu, J.; Chen, Z.; Han, L.; Ren, L. Review of grain threshing theory andtechnology. Int. J. Agric. Biol. Eng. 2018, 11, 12-20. [CrossRef]

8. Steponavičius, D.; Pužauskas, E.; Špokas, L.; Jotautienė, E.; Kemzūraitè, A.; Petkevičius, S. Concave design for high-moisture corn ear threshing. Mechanics 2018, 24. [CrossRef]

9. Kiniulis, V.; Steponavičius, D.; Kemzuraite, A.; Andriušis, A.; Juknevicius, D. Dynamic indicators of a corn ear threshing process influenced by the threshing-separation unit load. Mechanika 2018, 24, 412-421. [CrossRef]

10. Al Sharifi, S.K.A.; Aljibouri, M.A.; Taher, M.A. Effect of Threshing Machines, Rotational speed and grain moisture on corn shelling. Bulg. J. Agric. Sci. 2019, 25, 243-255.

11. Yu, Y.; Fu, H.; Yu, J. DEM-based Simulation of the corn threshing process. Adv. Powder Technol. 2015, 26, 1400-1409. [CrossRef]

12. Srison, W.; Chuan-udom, S.; Saengprachatanarug, K. Design factors affecting losses and power consumptionof an axial flow corn shelling unit. Songklanakarin J. Sci. Technol. 2016, 38. [CrossRef]

13. Chen, D.; Kang, F.; Zhu, Q.Y.; Wang, S.M. Study on combine harvester speed control based on optimum threshing power consumption model. Appl. Mech. Mater. 2011, 130-134, 1911-1914. [CrossRef]

14. Lu, N.Y.; Gong, G.X.; Yang, Y.; Lu, J.H. Multi-objective process parameter optimization for energy saving in injection molding process. J. Zhejiang Univ. Sci. A 2012, 13, 382-394. [CrossRef]

15. Xiao, W.; Wang, B.; Zhou, J.; Ma, W.; Yang, L. Optimization of aluminium sheet hot stamping process using a multi-objective stochastic approach. Eng. Optim. 2016, 48, 2173-2189. [CrossRef]

16. Li, H.; Chen, J.; Xiao, Y. Multi-objective optimization for laminated steel sheet forming process based on desirability function approach and reliability analysis. Eng. Comput. 2013, 30, 1107-1127. [CrossRef]

17. Zhu, F.; Wang, Z.; Lv, M. Multi-objective optimization method of precision forging process parameters to control the forming quality. Int. J. Adv. Manuf. Technol. 2015, 83, 1763-1771. [CrossRef]

18. Nisi, K.; Nagaraj, B.; Agalya, A. Tuning of a PID controller using evolutionary multi objective optimization methodologies and application to the pulp and paper industry. Int. J. Mach. Learn. Cybern. 2018, 10, 2015-2025. [CrossRef]

19. Torres-Treviño, L.M.; Reyes-Valdes, F.A.; López, V.; Praga-Alejo, R. Multi-objective optimization of a welding process by the estimation of the Pareto optimal set. Expert Syst. Appl. 2011, 38, 8045-8053. [CrossRef]

20. Kiniulis, V.; Steponavičius, D.; Andriušis, A.; Kemzūraitè, A.; Jovarauskas, D. Corn ear threshing performance of filler-plate-covered threshing cylinders. Mechanics 2017, 23, 714-722. [CrossRef]

21. Ren, L.Q. Design of Experiment and Optimiz-Ation; Higher Education Press: Beijing, China, 2009; pp. $246-257$.

22. Paulsen, M.R.; Nave, W.R. Corn damage from conventional and rotary combines. Trans. ASAE 1980, 23, 1100-1116. [CrossRef]

23. Konak, A.; Coit, D.W.; Smith, A.E. Multi-objective optimization using genetic algorithms: A tutorial. Reliab. Eng. Syst. Saf. 2006, 91, 992-1007. [CrossRef]

24. Petkevichius, S.; Shpokas, L.; Kutzbach, H.D. Investigation of the maize ear threshing process. Biosyst. Eng. 2008, 99, 532-539. [CrossRef]

25. Pishgar Komleh, S.H.; Keyhani, A.; Mostofi Sarkari, M.R.; Jafari, A. Assessment and determination of seed corn combine harvesting losses and energy consumption. Elixir Agric. 2013, 54, 12631-12637. [CrossRef]

(C) 2020 by the authors. Licensee MDPI, Basel, Switzerland. This article is an open access article distributed under the terms and conditions of the Creative Commons Attribution (CC BY) license (http://creativecommons.org/licenses/by/4.0/). 